\title{
The Role of Endoscopic Retrograde Cholangiopancreatography (ERCP) in the Management of Intra-Biliary Rupture of Liver Hydatid Cysts (IBRH): Follow-Up of 12 Cases
}

\author{
Mohammad Abdulrahman Alshekhani, Taha A. Alkarbuli, \\ Naser Abdullah Mohammed Alqazi, Hiwa A. Hussein, \\ Qalandar H. Kasnazan, Ali Hussein Ali \\ Kurdistan Center for Gastroenterology \& Hepatology, Asulaimaneyah, Iraqi Kurdistan, Iraq
Email: shaikhanimohammad@googlemail.com
}

Received 19 July 2014; revised 18 August 2014; accepted 16 September 2014

Copyright (C) 2014 by authors and Scientific Research Publishing Inc.

This work is licensed under the Creative Commons Attribution International License (CC BY). http://creativecommons.org/licenses/by/4.0/

(c) (i) Open Access

\section{Abstract}

Background: Intra-biliary rupture of hydatid cyst [IBRH] is not a rare complication of hydatid disease of the liver and surgery until recently is the only definitive treatment. With the introduction of ERCP preoperatively or postoperatively there was a great reduction in the operative complications. There were reports in which the ERCP was the sole treatment of this condition. Objective: To evaluate role of ERCP in the management of cases of IBRH. Design: A retrospective study of 7 cases of IBRH and prospective study of 5 cases of IBRH managed by ERCP. Setting: The ERCP Unit of Kurditan Center for Gastroenterology \& Hepatology, Asulaimaneyah-Iraqi, Kurdistan, Iraq. Main Outcome Measurements: Improvement in the symptoms, obstructive liver functions pattern and ultrasonic findings in these patients following ERCP management. Methods: This is a study of 12 cases of IBRH managed by ERCP in the Kurdistan Center of Gastroenterology (KCGE) in Asulaimaneyah-Iraq, from 2007-2010. Seven cases of these were studied retrospectively from the available information on the center computers and on follow-up of these patients, while the other five patients were studied prospectively during the study period. We collected the available information: laboratory investigations, trans-abdominal ultrasonography (TAUS), computed tomography (CT) or magnetic resonance images (when available), before and after ERCP. We depended on the liver functions, trans-abdominal ultrasound and the clinical presentation before and after the ERCP; some patients were contacted via mobile phone for follow-up. Results: Cases were more males than females ( $58 \%$ vs $42 \%$ ); most were from the ages between 30 - 50 years. The clinical presen- 
tation was fever, jaundice, itching and right hypochondrial pain in most patients. The liver function tests were obstructive pattern with elevated direct bilirubin and alkhaline phosphates in most patients. The trans-abdominal ultrasound revealed dilated common bile duct and single liver cyst in most patients and 2 or 3 cysts in others. The ERCP management led to improvement in clinical, laboratory and ultrasonic findings in 6 patients and in these 6 patients ERCP was the only procedure needed and proved by follow-up of these patients for 1 year in 4 patients and 2 years in the other 2 patients, especially in those with hydatid mebranes seen at ERCP and those with cholangiographic evidence of communication with the cyst; surgery was needed in 5 cases and one patient died from septic shock. Conclusions: ERCP is an important management strategy for patients with IBRH, which can lead to clinical, laboratory and ultrasonographic improvements, and can be the only required procedure in more than $50 \%$ of cases especially in those with hydatid mebranes seen at ERCP and those with cholangiographic evidence of communication with the cyst.

\section{Keywords}

\section{Intra-Biliary Rupture of Hydatid Cyst, ERCP, Obstructive Jaundice}

\section{Introduction}

Intra-biliary rupture of hydatid cyst is not a rare complication with communication between the liver and hydatid cyst being present in $80 \%-90 \%$ of cases, but the incidence of clinical communication is from (13\% - 37\%) [1] [2]. Intrabiliary rupture occurs into the right duct in 55\% - 60\% of cases, into the left duct in $25 \%-30 \%$ and rarely into the confluence or gall bladder [3] [4]. There are three types of communications: the occult one when the endocyst or cyst contents remain within the pericyst, communicating type where the cystic contents spill in to the small biliary canaliculi, and the third type is the frank rupture with most of the contents of the cyst spill to the biliary tract; these represent $5 \%-7 \%$ and the patient complain of right hypochondria pain, fever and jaundice [1] [2] [5].

The diagnosis of intra-biliary rupture of hydatid cyst (IBRH) was difficult before the introduction of transabdominal ultrasound (TAUS), by which the sensitivity for detection of frank rupture is $60 \%-90 \%$ [6] [7] and reaching $100 \%$ [6] [8] with the use of comouted tomography scan (CT scan). Some centers also advocate magnetic resonance image (MRI) in the diagnosis of IBRH, and recently endoscopic ultrasound (EUS) has been introduced in the diagnosis of IBRH particularly in India [9]. If obstructive jaundice is present TAUS, CT scan and MRI can show the cyst and the cystobiliary communications, but in patient with no jaundice the correct diagnosis can be done only in 25\% [8]. IBRH is a serious complication of hepatic hydatidosis. High intracystic pressure up to $80 \mathrm{~cm}$ water is a predisposing factor [8]. Preoperative ERCP may demonstrate frank rupture, but occult IBRH cannot be demonstrated by ERCP because of high intracystic pressure and small communication [1]. An enlarging cyst may compress the surrounding paranchyma causing atrophy and fibrosis [6]. The increase in the pressure inside the cyst precipitated by trauma, effort, labor or violent cough, could lead to rupture to the biliary tract or even the lung pleura or peritoneum, moreover acute pancreatitis and acutecholycystitis had been reported [10]. Trans-abdominal ultrasonography may suggest the diagnosis of IBRH with the sensitivity from (64\% - 94\%) and the accuracy increase to (100\%) by using CT scan [6] [7] [10]. There are several TAUS criteria for diagnosis of IBRH including the following [6]:

1) Ruptured cyst is often multi-vesicular, polycystic, septae \& with echogenic material inside.

2) Loss of cystic wall continuity adjacent to bile ducts is pathognomonic sign of communication.

3) Dilatation of biliary tree in the presence of liver hydatid cyst.

4) Echogenic material inside the CBD is specific sign but not sensitive.

5) Thickened, doubled layer bile duct wall is seen only after endoscopic removal of hydatid cyst fragments.

6) The CBD diameter change in previously diagnosed liver hydatidcyst, is diagnostic of IBRH with certainty [7].

The accepted treatment of IBRH is surgery in the form of radical hepatic resection and total pericystectomy, although conservative treatment in the form of cyst evacuation termed percutaneous aspiration injection repair (PAIR) followed by capsuloraphy or external drainage has been reported [1] [2] [7]. Surgical treatment some- 
times is followed by complications like biliary cutaneous fistula, biloma and bile peritonitis in the frequency (4\% - 28\%) [5]. With the introduction of endoscopic retrograde pancreatico-cholangiography (ERCP) pre- or post-operatively, these complications were greatly reduced [2]. The RECP interventions include sphincterotomy with or without stenting, nasobiliary drainage and balloon dilatation followed by evacuation making ERCP to play a pivotal role in the diagnosis and therapeutic treatment of IBRH [1] [5]. Until recently, ERCP is used as adjunct to surgery pre- or post-operatively to reduce surgical complication and the role of ERCP in the nonoperative management was described only in case reports or small case series [1] [2] [5] [11] [12]. The aim of this study is to evaluate the role of ERCP in IHRH in the largest case series studied till now [11] [12].

\section{Patients \& Methods}

This is a study of 12 case series of IBRH managed by ERCP in the Kurdistan center of gastroenterology (KCGE) in Asulaimaneyah-Iraq, from $1^{\text {st }}$ January $2007-1^{\text {st }}$ January 2010. The duodenoscope was of the olypmus type. Seven cases of these were studied retrospectively from the available information on the center computers \& on follow-up of these patients, while the other five patients were studied prospectively during the study period. We collected the available information: laboratory investigations, ultrasonography (US), computed tomography (CT) or magnetic resonance images (when available), before and after ERCP. We depended on the liver functions, trans-abdominal ultrasound and the clinical presentation before and after the ERCP \& some patients were contacted via mobile phone for follow-up. Dramatic improvement was defined as complete symptomatic improvement with normalization of the liver function tests \& imaging abnormalities with exception of remnant cyst cavities or smaller cysts or persistence of small non-ruptured ones.

\section{Results}

There were 12 cases from ages between 10 - 79 years. Seven cases were male (58\%) and five cases were female (41\%), two cases aged $10 \& 19$ years and one case aged 26 years, 2 cases $30 \& 39$ years, 4 cases from 40 - 49, one cases aged 58 and 2 cases $70 \& 79$ as shown in Table 1 . We can see that the most cases were between 30 50 years of age.

The clinical presentation were; fever in 10 (83\%) cases, right hypochondria pain 8 cases (66\%) and jaundice in all cases as shown in Table 2.

Table 1. The frequency and the age of the patients.

\begin{tabular}{ccc}
\hline Age range (years) & Frequency & Percentage \\
\hline $10-19$ & 2 & 16.7 \\
$20-29$ & 1 & 8.3 \\
$30-39$ & 2 & 16.7 \\
$40-49$ & 4 & 33.3 \\
$50-59$ & 1 & 8.3 \\
$70-79$ & 2 & 16.7 \\
Total & 12 & 100 \\
\hline
\end{tabular}

Table 2. The clinical presentation of the cases.

\begin{tabular}{ccc} 
The clinical presentation & Frequency & Percentage \\
Jaundice, fever \& right hypochondrial pain & 7 & 3.3 \\
Jaundice \& fever & 25 & 1 \\
Jaundice \& right hypochondrial pain & 8.3 & 1 \\
Jaundice & 8.3 & 12 \\
Total & 100 & 12 \\
\hline
\end{tabular}


The ultrasonic finding including the number of hepatic cysts and the diameter of the common bile duct (CBD) were studied. Those cases that had one liver cyst were 8 (66\%), one case had two liver cysts (8\%) \& 3 cases (25\%) had three liver cysts and above as shown in Table 3. The CBD diameter was of $<8 \mathrm{~mm}$ in three cases, from $8-14 \mathrm{~mm}$ in eight cases and $>14 \mathrm{~mm}$ in two cases as shown in Table 4. Image 1 and Image 2 show the ultrasonographic features of ruptured cysts in 2 of our cases.

The common bile duct diameter of the patients assessed by abdominal ultrasonography, CT \& MRCP is shown in Table 5. Image 3 and Image 4 show the CT \& MRCP findings of the ruptured cysts in some of our cases.

Table 5 shows ERCP findings and the endoscopic interventions that included shincterotomy with evacuation of the biliary tract from hydatid contents \& daughter cysts. The Image 5 show the choalangiogrphic findings of ruptured liver hydatid in one of the cases \& the Images 6-11 show the endoscopic findings of ruptured liver hydatid cysts in some of the cases.

The outcome of the patients managed by ERCP is shown in Table 6. Dramatic improvement was noticed in 6 patients defined as complete symptomatic improvement with normalization of the liver function tests \& imaging abnormalities with exception of remnant cyst cavities or the cysts becoming smaller or persistence of small

Table 3. The number of cysts assessed by abdominal ultrasonographic, CT \& MRCP findings of the patients.

\begin{tabular}{ccc}
\hline Number of cysts & Frequency & Percentage \\
\hline One cyst & 8 & 66.7 \\
2 cysts & 1 & 8.3 \\
3 and more cysts & 3 & 25 \\
Total & 12 & 100 \\
\hline
\end{tabular}

Table 4. Common bile duct diameter of the patients assessed by abdominal ultrasonography, CT\& MRCP.

\begin{tabular}{ccc}
\hline Common bile duct diameter & Frequency & Percentage \\
\hline Less than $8 \mathrm{mms}$ & 2 & 16.7 \\
$8-14 \mathrm{mms}$ & 8 & 66.7 \\
More than $14 \mathrm{mms}$ & 2 & 16.7 \\
Total & 12 & 100 \\
\hline
\end{tabular}

Table 5. ERCP findings \& therapeutic interventions done in the cases with IBRH.

\begin{tabular}{ccc}
\hline ERCP finding & Number (\%) & Dramatic response to ERCP \\
\hline Filling defects in CBD & $6(50 \%)$ & 1 \\
Hydatid membrane protruded through ampulla & $3(25 \%)$ & 3 \\
Cholangiographic communication with the cyst(s) & $3(25 \%)$ & P $<0.05$ \\
Total & $12(100 \%)$ & \\
\hline
\end{tabular}

Table 6. The outcome of the patients managed by ERCP.

\begin{tabular}{ccc}
\hline Outcome of patients managed by ERCP & Frequency & Percentage \\
Improved dramatically & 6 & 50 \\
Improved partially \& referred for surgery & 5 & 41.7 \\
Death due to septic shock & 1 & 12 \\
Total & 100 \\
\hline
\end{tabular}




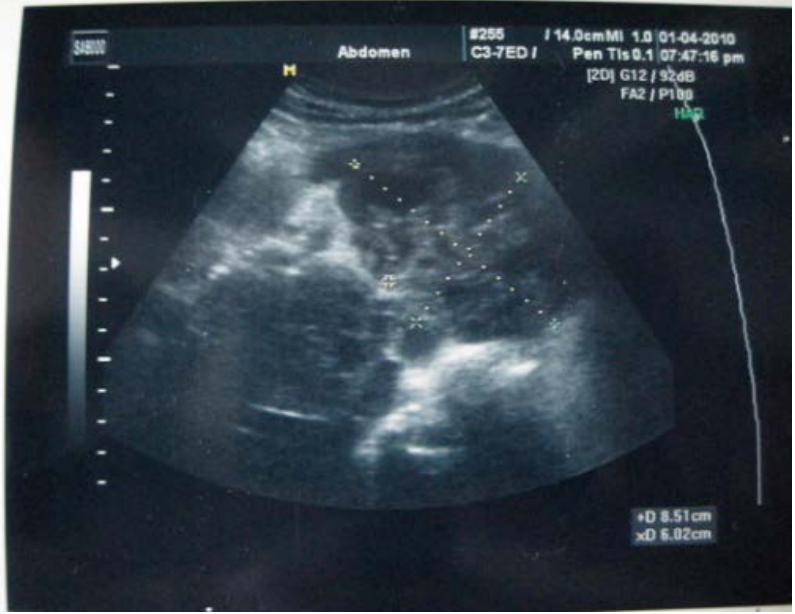

Image 1. TAUS showing IBRH with biliary communication.

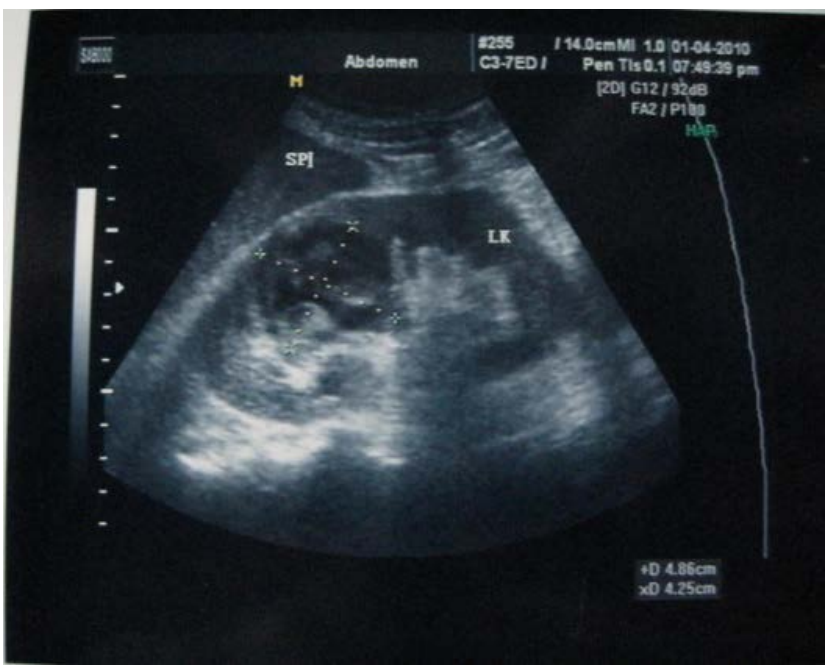

Image 2. TAUS showing IBRH with biliary communication.

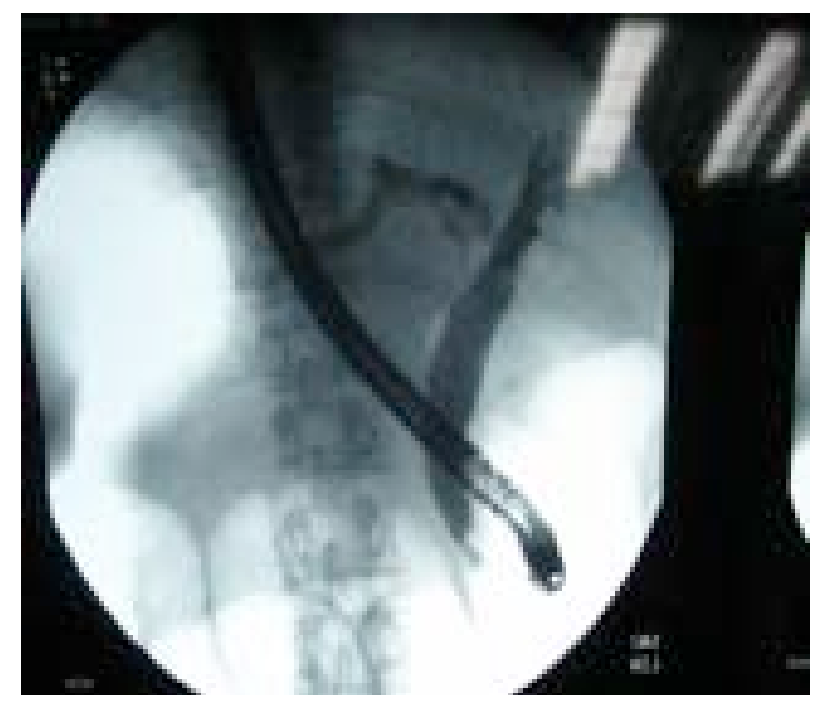

Image 3. ERCP showing biliary dilation with filling defects. 


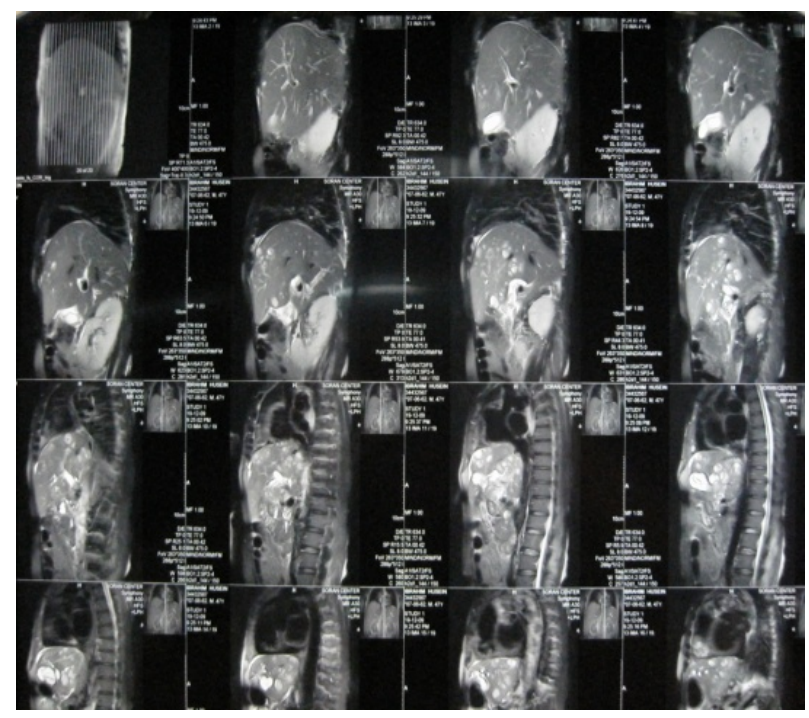

Image 4. MRCP with multiple liver cysts.

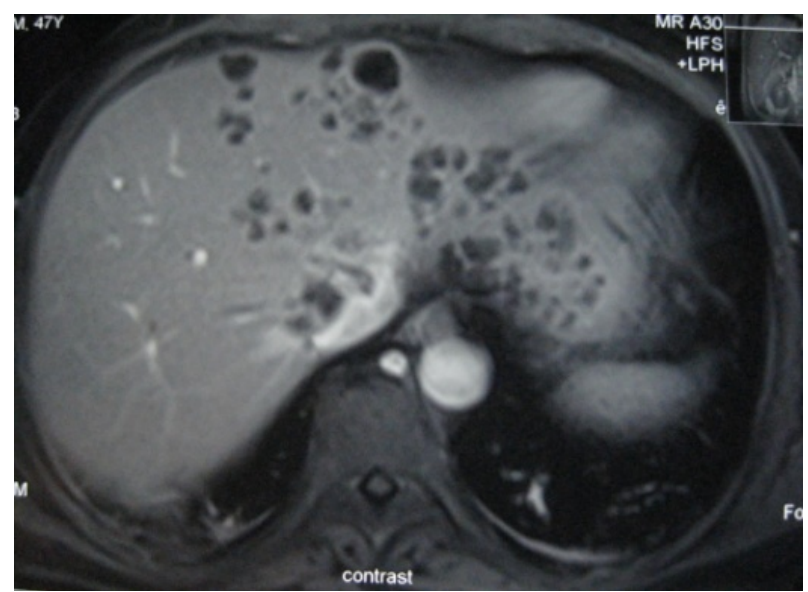

Image 5. MRI showing multiple liver cysts in one of the 12 cases.

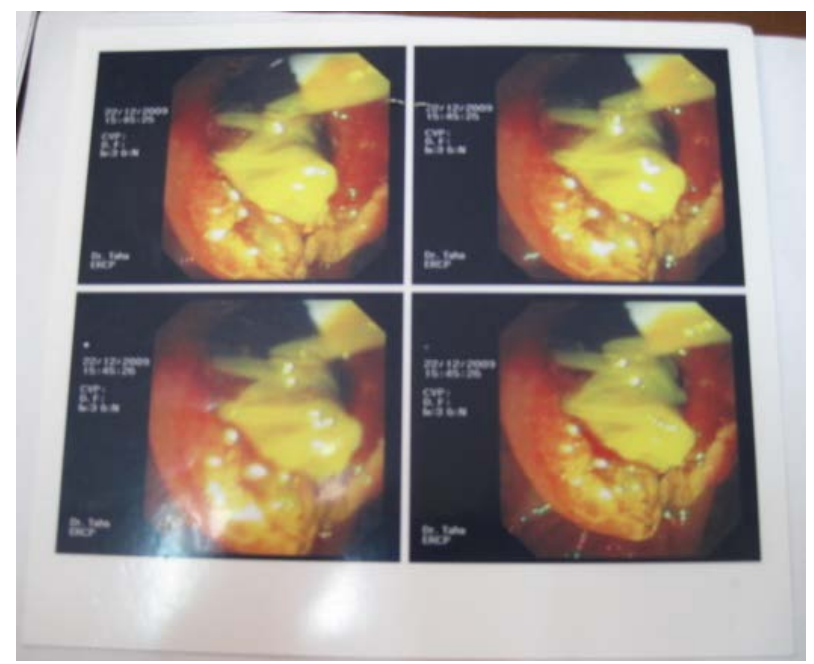

Image 6. Impacted hydatid membrane at ampulla of Vater. 


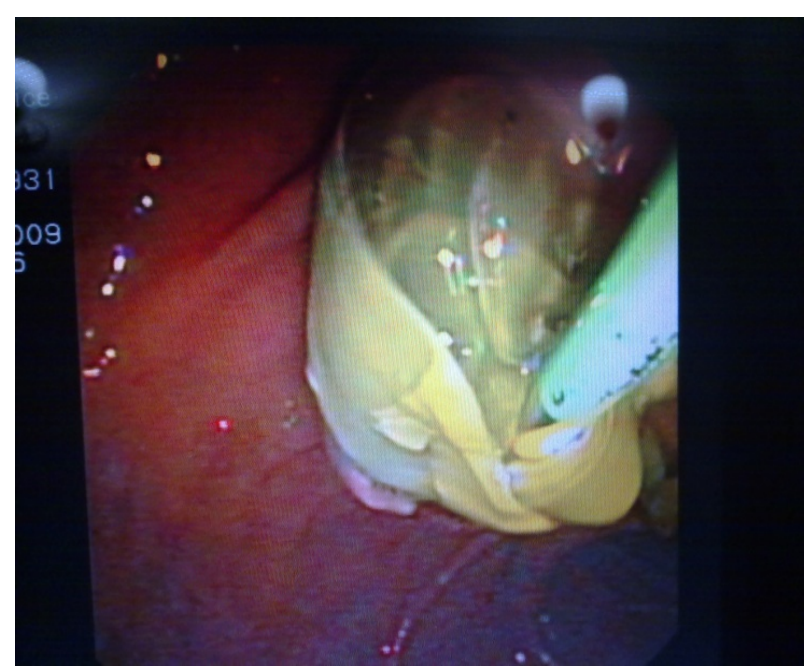

Image 7. Impacted hydatid membranes at ampulla of Vater.

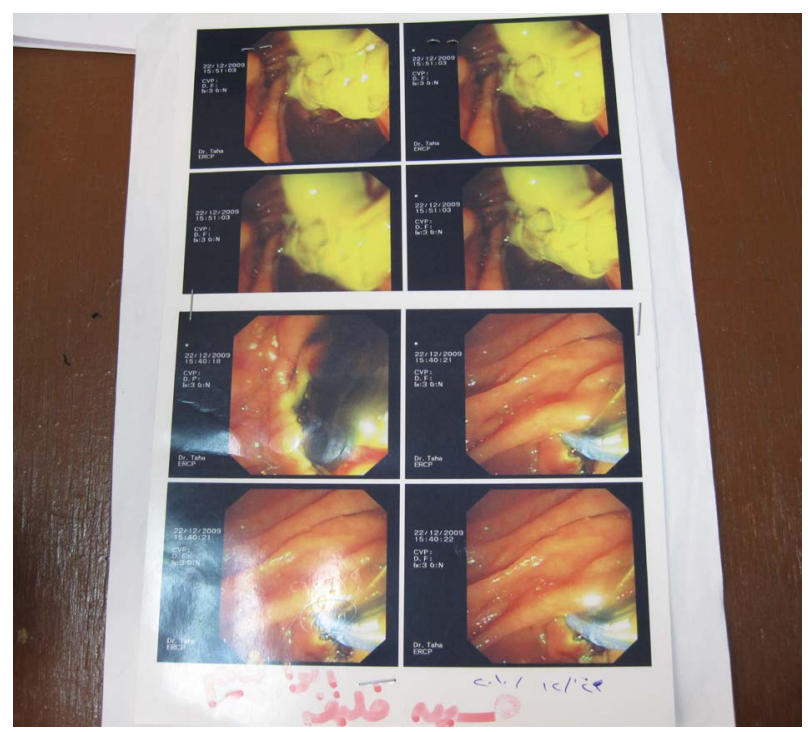

Image 8. Infected hydatid membranes drained by ERCP.

non-ruptured ones. Those who had dramatic improvement, remained such during the period of the study on follow up \& didn't required referral to surgery, while the other 5 patients didn't show such dramatic improvement \& required referral for surgical management of the liver cysts. One case had died, because she had comorbid diseases of uncontrolled diabetes \& hepatitis $C$ virus infection which may have contributed to severe septic shock that caused her demise in spite of ERCP \& aggressive management in intensive care unit.

Images 1-11 include some of the images of the cases in this study including ERCP endoscopic \& cholangiographic images, TAUS images \& MRI images.

\section{Discussion}

The hydatid cyst is a parasitic disease mainly caused by Echinococcus granulosus. It is common in Mediterranean countries, the Middle East, the Far East, Europe, Asia, South America and Australia. In human the most infested organ are the liver and the lung. Most patients have a solitary cyst, located in two thirds of cases in the liver [6].

In the Table 1, most patients were between 20 - 50 years representing (66.6\%), this in comparable to other studies [5] [8]. 


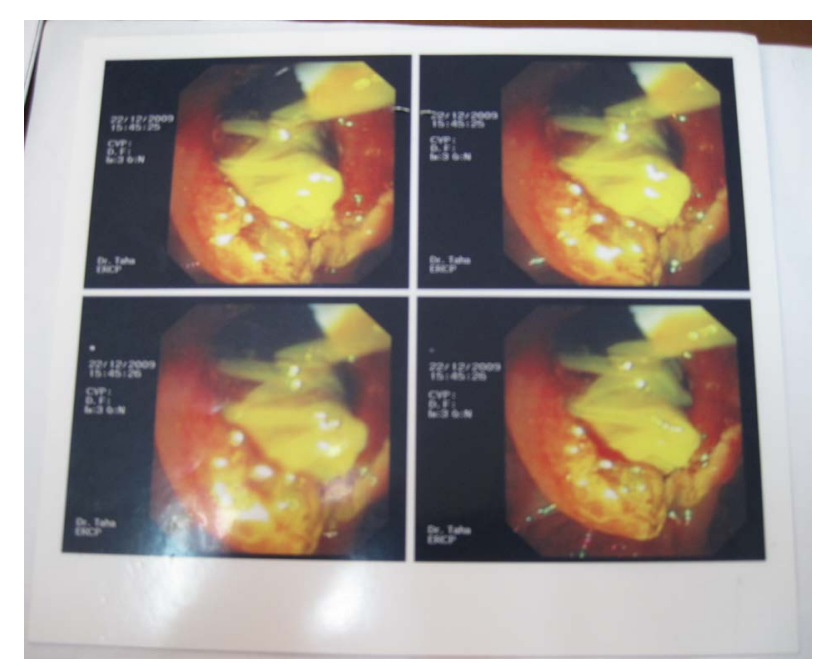

Image 9. Infected hydrated membranes in the duodenum drained by ERCP.

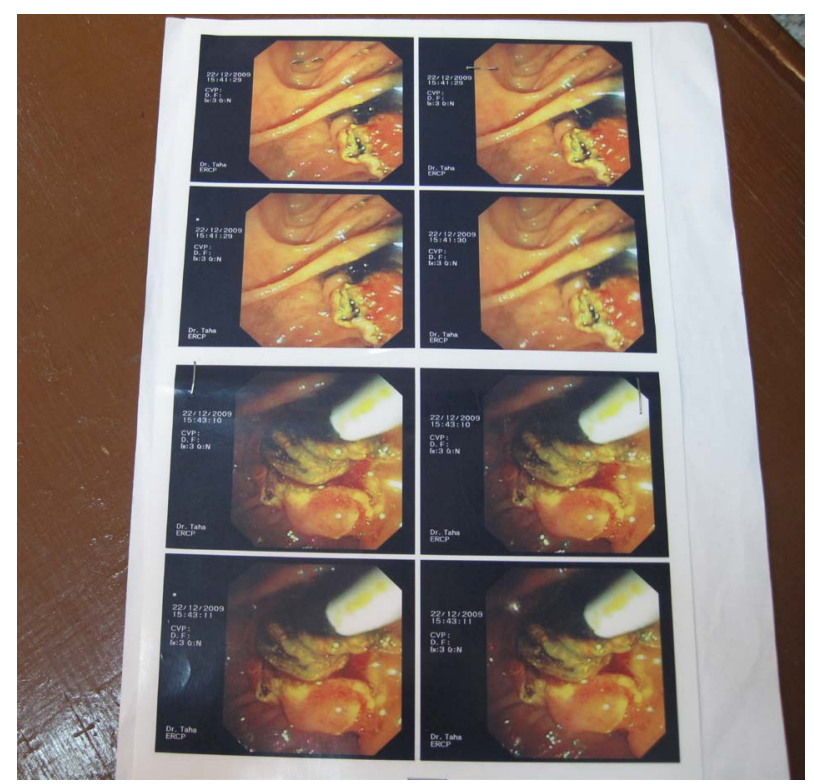

Image 10. Infected hydrated membranes in the duodenum drained by ERCP.

The male affected more than female; 7 males versus 5 females, this is also comparable with some studies [1] [2] while in other studies female were more [7]. This is probably due to males working out doors more than females in our locality.

Table 2, shows that the main presenting feature was jaundice being present in all 12 cases $(100 \%)$ this is either alone in one case (8.3\%) or associated with right hypochondrial pain in one case (8.3\%), 7 cases (58.5\%) presented with frank cholangitis, with fever, jaundice and right hypochondrial pain, and jaundice and fever in 3 cases (25\%). In a study all cases presented with right hypochondrial pain and (50\%) presented with obstructive jaundice [7]. In other study right hypochondrial pain was present in (79\%) and obstructive jaundice with increase serum bilirubin and alkaline phosphatase in (95.7\%) and (24.4\%) respectively [1]. in other studies, cholangitis was found in (20\% - 27\%) of cases and fever in (60\% - 93\%) of cases [5]. This different presentation may be related to the degree of rupture or communication $\&$ the associated cholangitis. In this study three cases showed the hydatid membrane protruding through the amplla of Vater during ERCP.

In Table 3 there is eight cases (66.6\%) had 1 cyst and one case (8.3\%) had 2 cysts, the remaining cases there 


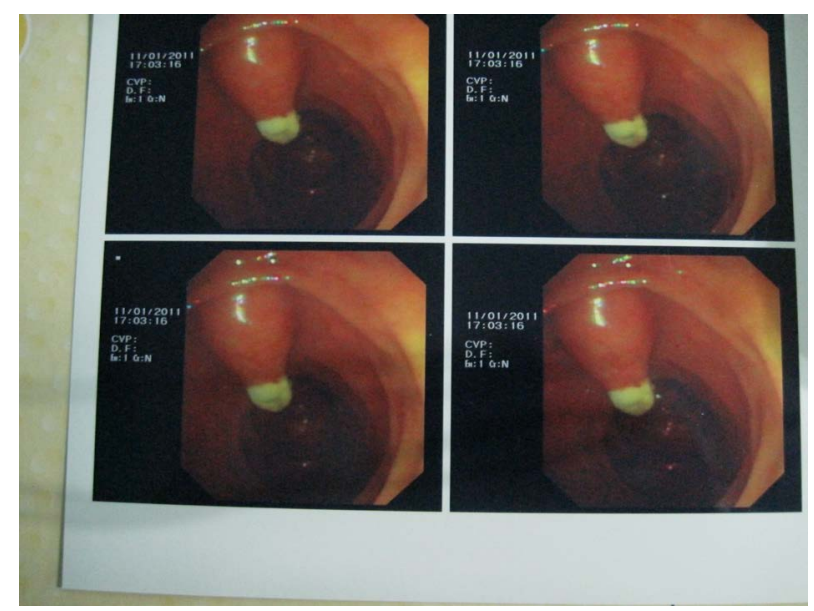

Image 11. Hydatid membrane pointing at ampulla of Vater during ERCP.

is 3 or more cysts (25\%). The number of cysts in the liver does not affect the management [10] because the other cysts might remain silent and may not increase in size to have such pressure to cause rupture but may need follow up and even might regress with the medical treatment [10]. In one study 50\% of cases had 1 cyst and 25\% of cases had 2 cysts and $25 \%$ with 3 cysts or more [5].

In Table 4, the CBD diameter ranged from $<8 \mathrm{~mm}$ in 2 cases and 8 cases from $8-14 \mathrm{~mm}$ while the last 2 cases $>14 \mathrm{~mm}$.

Table 5 shows the ERCP findings in the cases which included either seeing the hydatid membrane protruding through the ampulla (3 cases) or seeing filling defects in the dilated CBD (6 cases) or demonstrating clear cholangiographic communication with the cyst or cysts (3 cases). In all of these cases the ERCP therapeutic intervention was sphincteromy with evacuation of all the memebranes and daughter cysts from the biliary tract with or without using extraction balloon. In all of the cases with suspected IBRH, ERCP provided the definitive diagnosis \& therapeutic procedure of choice for the evacuation of the biliary system. This table also shows that the cases that had dramatic improvement to ERCP interventions, were mostly those that had evidence of cholangiographic connection of biliary connection with the cyst or those that had the hydatid membrane protruded through the ampulla of Vater. The explanation of this finding may be that these cases had more complete evacuation of the cyst contents into the biliary system that causing dramatic response to ERCP intervention \& didn't need surgical intervention. In single case reports, ECRP provided definitive treatment in some of these case reports [1] [2] [6] [8] [9]. In case series reported till now that included smaller number of cases than this current case series (8 10 patients), ERCP was used as adjunct to surgery to reduce surgical complication or to treat post operative complication rather than using in a curative intent and to study the predictive features of dramatic response to ERCP intervention, like the current study [10]-[13]. In reported cases and case series, ERCP provided more comprehensive information, the daughter cyst had been seen in the duodenum, impacted in the ampulla of Vater or obstructed any part of the biliary tree \& the intra-biliary parasite material appeared as non homogenous irregular shaped and mobile filling defect [2]. The other findings were dilatation and displacement of the intrahepatic bile ducts by hepatic cyst, intrahepatic duct stricture and mild dilatation of the pancreatic duct \& helped to differentiate IBRH from other cause of obstructive jaundice [6]. In Table 6, the cases presented as IBRH and treated by ERCP were twelve; six of them had dramatic improvement \& remained so during the study period, so there was no need to refer them to surgery. The other six patients, five of them, required surgery because of incomplete evacuation of the small biliary tree that contained cyst fragments \& one patient died before surgery from septic shock because of the presence of comorbid illnesses namely hepatitis $\mathrm{C}$ virus infection \& uncontrolled diabetes mellitus. The major role of ERCP in IBRH is mainly a therapeutic one [5] [10]. The first published report of the role of ERCP in IBRH with endoscopic sphincterotomy and extraction of retained material \& daughter cysts from the CBD was in 1985 [6]. ERCP, although minimally invasive, it is not without risk including infection, bleeding and acute pancreatitis that may need repeat endoscopy or immediate surgical intervention, but it is less invasive than surgery \& can be performed safely and efficiently even in very old person with the increased comorbidity $\&$ risk of post-operative complications, moreover it is advocated as pre and post operative 
procedure, with sphicterotomy to drain \& clean the infected biliary tree [13]-[22].

\section{Conclusion and Recommendations}

ERCP is an important management strategy for patients with IBRH, which can lead to dramatic clinical and laboratory improvements, and can be the only required procedure in around 50\% of cases. We recommend that ERCP should be the first therapeutic strategy in patients presented with IBRH, because it is minimally invasive and can save around $50 \%$ of cases from unnecessary surgery.

\section{References}

[1] Demircan, O., Baymus, M., Seydaoglu, G., Akinoglu, A. and Sakman, G. (2006) Occult Cystobiliary Communication Presenting as Post Operative Biliary Leakage after Hydatid Liver Surgery: Are There Significant Preoperative Clinical Predictors. Canadian Journal of Surgery, 49, 177-184.

[2] Chautems, R., Bühler, L.H., Gold, B., Giostra, E., Poletti, P., Chilcott, M., et al. (2005) Surgical Management and Long Term Outcome of Complicated Liver Hydatid Cyst Caused by Echinococcus granulosus. Surgery, 137, 312-316. http://dx.doi.org/10.1016/j.surg.2004.09.004

[3] Akkiz, H., Akinoglu, A., Colakoglu, S., et al. (1996) Endoscopic Management of Biliary Hydatid Disease. Canadian Journal of Surgery, 39, 287-292.

[4] Kumar, R., Reddy, S.N. and Thulkar, S. (2002) Intrabiliary Rupture of Hydatid Cyst: Diagnosis with MRI and Hepatobiliary Isotope Study. British Journal of Radiology, 75, 271-274. http://dx.doi.org/10.1259/bjr.75.891.750271

[5] Avecu, S., Ünal, Ö. and Arslan, H. (2009) Intrabiliary Rupture of Hydatid Cyst: A Case Report and Review of Literature. Cases Journal, 2, 1757-1762.

[6] Spârchez, Z., Osian, G., Onica, A., Bârbântâ, C., Tanţâu, M. and Pascu, O. (2004) Rupture Hydatid Cyst of the Liver with Biliary Obstruction: Presentation of a Case and Review of the Literature. Romanian Journal of Gastroenterology, 13, 245-250.

[7] Erzurmlu, K., Dervisoglu, A., Polat, C., Senyurek, G., Yetim, I. and Hokelek, M. (2005) Intrabiliaryrupture: Analgorithmin the Treatment of Controversial Complication of Hepatic Hydatidosis. World Journal of Gastroenterology, 11, 2472.

[8] Choh, N.A., Choh, S.A. and Jehangir, M. (2008) Intrabiliary Rupture of Hydatid Cyst Demonstrated by Magnetic Resonance Cholangiopancreatography. Archives of Disease in Childhood, 93, 441. http://dx.doi.org/10.1136/adc.2008.138354

[9] Sharma, M., Somasundaram, A., Pathak, A., et al. (2010) Endoscopic Ultrasound in Hepatobiliary Hydatid Disease. Endoscopy, 42, E56-E57. http://dx.doi.org/10.1055/s-0029-1243830

[10] Izadpanah, A. and Saidi, F. (2006) Asymptomatic Liver Hydatidcysts; a Preferred Approach. Iranian Journal of Medical Sciences, 31, 1-4.

[11] Özaslan, E. (2006) Therapeutic Endoscopic Retrograde Cholangiopancreatography and Related Modalities Have Many Roles in Hepatobiliary Hydatid Disease. World Journal of Gastroenterology, 12, 4930-4931.

[12] Galati, G., Sterpetti, A.V., Caputo, M., Adduci, M., Lucandri, G., Brozzetti, S., et al. (2006) Endoscopic Retrograde Cholangiography for Intrabiliary Rupture of Hydatid Cyst. The American Journal of Surgery, 191, 206-210. http://dx.doi.org/10.1016/j.amjsurg.2005.09.014

[13] (2006) 14th United European Gastroenterology Week (UEGW). Berlin, 21-25 October 2006, Selected Endoscopy Reports.

[14] Saouab, R., Semlali, S., Mahi, M., Amil, T., Hanine, A., Benameur, A. and Chaouir, S. (2010) Intrabiliary Rupture of Hydatid Cyst: Imaging Findings. Mohamed 5th Military Hospital, Rabat-Morocco.

[15] Khuroo, M.S. (2002) Hydatid Disease: Current Status and Recent Advances. Annals of Saudi Medicine, 22, 56-64.

[16] Mentes, O., Yigit, T., Ozer, T., Uzar, A.I., Kozak, O., Arsalan, I. and Tufan, T. (2006) Unexpected Complication of Liver Hydatid Cyst Disease: A Frank Rupture to Biliary Channels at Both Main Sides: Report of a Rare Case. Balkan Military Medical Review, 9, 161-163.

[17] Saracino, A., Scotto, G., Ciavarella, G., Natale, C., Palumbo, E., Cibelli, D.C. and Angarano, G. (2004) Intrabiliary Rupture of Ahydatid Liver Cyst: A Case Report. The New Microbiologica, 27, 301-303.

[18] Emre, A., Arioğul, O., Alper, A., Ökten, A., Uras, A. and Yalçin, S. (1990) Hydatid Cysts of the Liver and Portal Hypertension. HBP Surgery, 2, 129-133.

[19] Sumer, A., Caglayan, K., Altinli, E. and Koksal, N. (2009) Case Report: Spontaneous Liver Hydatidcystrupture in a Child. Israeli Journal of Medicine, $\mathbf{9}$. 
[20] Sahin, D.A., Kusaslan, R., Sahin, O. and Dilek, O.N. (2007) Hugehydatid Cysts That Arise from the Liver, Growing Exophytically. Canadian Journal of Surgery, 50, 301-303.

[21] Reddy, D.N. (2009) Endoscopic Diagnosis and Management of Biliary Parasitosis.

[22] Lewall, D.B. and McCorkell, S.J. (1986) Rupture of Echinococcal Cysts: Diagnosis, Classification, and Clinical Implications. American Journal of Roentgenology, 146, 391-394. http://dx.doi.org/10.2214/ajr.146.2.391 
Scientific Research Publishing (SCIRP) is one of the largest Open Access journal publishers. It is currently publishing more than 200 open access, online, peer-reviewed journals covering a wide range of academic disciplines. SCIRP serves the worldwide academic communities and contributes to the progress and application of science with its publication.

Other selected journals from SCIRP are listed as below. Submit your manuscript to us via either submit@scirp.org or Online Submission Portal.
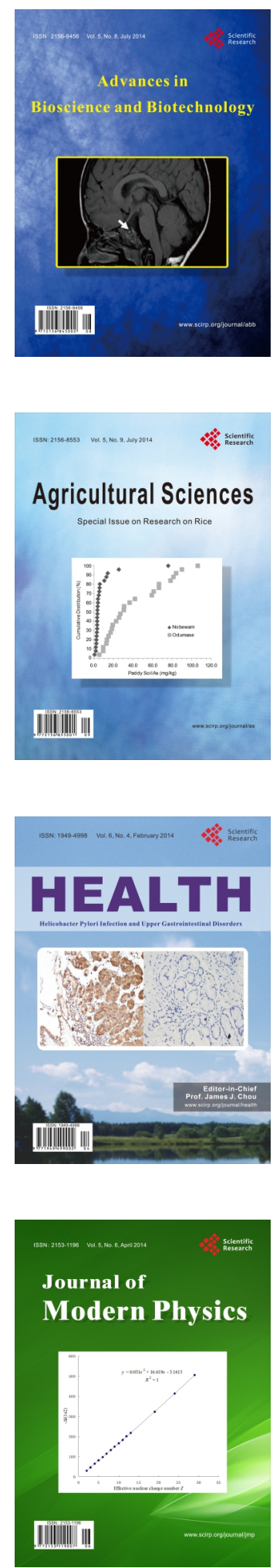
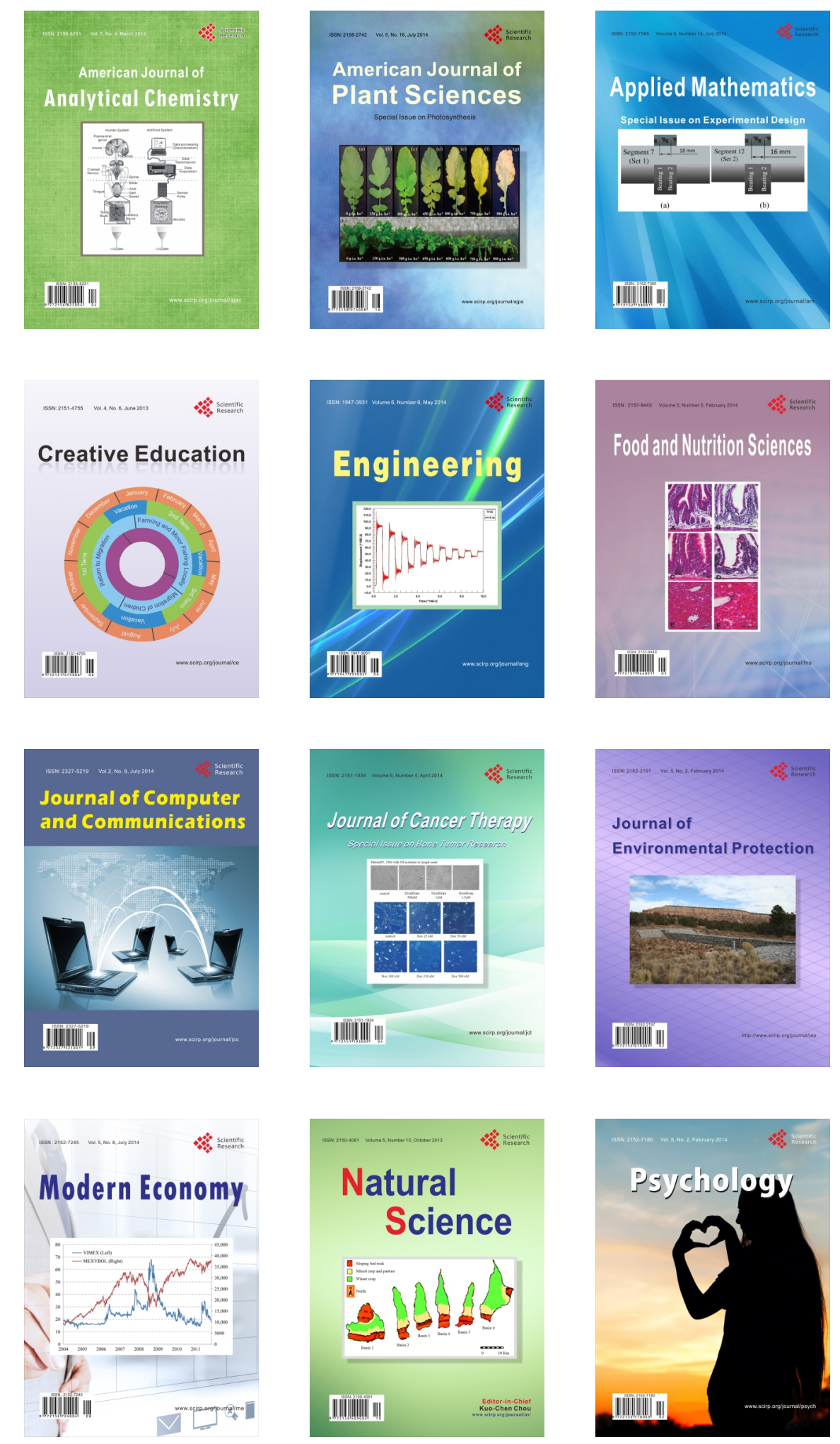